\title{
Association between road safety habits and risky health behaviours in Latvian adult population
}

\author{
Aija Bukova-Zideluna ${ }^{1, *}$, Anita Villerusa $^{1}$, and Iveta Pudule $^{2}$ \\ ${ }^{1}$ Riga Stradins University, Department of Public Health and Epidemiology, Riga, Latvia \\ ${ }^{2}$ Centre for Disease Prevention and Control, Department of Research and Health Statistics, Riga, Latvia
}

\begin{abstract}
The study examined the road safety habits of the adult population of Latvia in relation to risky health behaviours (smoking, excessive alcohol consumption, no regular health check-ups at the family doctor). Data of Health Behaviour among the Latvian Adult Population for five consecutive surveys for the years 2010-2018 were analysed. Results: The use of seat belts has increased slightly - from $93.5 \%$ to $95.6 \%$ in the front seat of the vehicle, from $52.4 \%$ to $56.3 \%$ in the rear seat of the vehicle $(p<0,001)$. Of the 10,731 respondents, $30.8 \%$ ( $N=3309$; $95 \%$ CI $30.0-31.7)$ were daily smokers, $14.8 \%$ $(N=1593$; $95 \%$ CI 14.2-15.5) had excessive alcohol consumption habits, $25.9 \%(N=2779 ; 95 \%$ CI $25.1-26.7)$ had not visited their family doctor during the last year. Higher odds for seat belt use were observed among respondents without excessive alcohol consumption $(\mathrm{OR}=2.1)$, non-smokers $(\mathrm{OR}=1.5-$ $1.8)$, and those, who had visited their family doctor last year $(\mathrm{OR}=1.2-1.3)$. Multivariate regression analysis showed risky behaviour is an independent factor associated with road safety habits.
\end{abstract}

Key words - road safety, use of seat belt, alcohol, smoking, family doctor.

\section{Introduction}

Road traffic collisions and injuries have been recognized as an increasingly significant global public health issue. Not only about 1.25 million people die each year because of road traffic collisions and about 50 million are injured worldwide, but road traffic injuries are also among the top ten leading causes of disability-adjusted life years [1]. World Health Organization also has estimated that road traffic collisions are set to become the seventh leading cause of death by 2030, if there is no intervention [2].

When analysing the number of deaths in road traffic collisions in 2018, European roads are recognized as the safest in the world (on average 49 deaths per million inhabitants). Although progress is being made in several areas, Latvia has still one of the highest road traffic fatality rates among the 28 European Union Member States (78 deaths per million inhabitants) [3]. According to Sustainable Development Goals designed globally, the national level target of a $50 \%$ reduction in road traffic-related fatalities and serious injuries by 2030 is set in Latvia [4].

\footnotetext{
*Corresponding author: aija.bukova@rsu.lv
} 
It has been estimated that wearing a seat belt reduces the risk of death among drivers and the front seat passengers by $45-50 \%$, and the risk of death and serious injuries among rear seat passengers by $25 \%$ [2]. Failure to use seatbelts is the second biggest cause of road deaths, after speeding and ahead of drink-driving. A study carried out for the European Commission has concluded that, in the best-case scenario, actions targeting the use of seatbelts would save 5,500 lives per year in the European Union [5].

The current paradigm emphasises road traffic injuries as a predictable and thus, also preventable event. Previous studies have shown that seat belt use is associated with occupant's age, gender, vehicle age, time of the day, geographic location, and different kind of enforcements [6-10]. Nevertheless, not only information on demographic and socio-economic factors characterizing an individual is used in the planning of interventions. In developing a deeper understanding of associations and relations, other health-related factors such as risky behaviour of the population are also relevant. If interventions on wearing seat belts are not enforced, they cannot bring about the expected reduction in road traffic fatalities and injuries related to safety habits.

The aim of the study was to examine the road safety habits of the adult population of Latvia in relation to risky health behaviours - smoking, excessive alcohol consumption, no regular health check-ups at the family doctor.

\section{Methods}

A representative sample of the Latvian population was used to conduct surveys in the Health Behaviour among Latvian Adult Population study. In each survey year (2010, 2012, 2014, 2016 and 2018), the sampling was based on multi-stage random stratified selection with quota elements, ensuring representation of all major socio-demographic groups (gender, age, place of residence and nationality). The study tool was a validated, standardised questionnaire, including data from 10,731 respondents (age 15-74).

Such road safety habits of the respondents as the use of seat belts in the front and rear seats of the vehicle, were selected as dependent variables. Excessive alcohol use, smoking and not using state-provided preventive health services were considered risky health behaviours. Excessive alcohol use was defined for respondents who had consumed at least six units of alcohol in a single setting last month. Everyday smoking is considered risky health behaviour. Respondents were considered to have careless health behaviour if they had not visited their family doctor in the past year. For all respondents' demographic and socioeconomic information - gender, age and level of education - was collected and analysed.

The data was analysed using descriptive statistics, Pearson's chi-square test and calculations of statistical significance using SPSS for Windows 23.0. T-test and logistic regression analyses were conducted to compare the unsafe road habits with others in terms of sociodemographic and other health related behavioural outcomes. The 95\% confidence interval (CI) was used to estimate the precision of the odds ratio (OR).

\section{Results}

The use of seat belts in the front seat is relatively high - they are usually used by $93.1 \%(N=$ 9989; 95\% CI 92.6-93.6) of a total of 10,731 respondents. Analysing the trends in the period from 2010 to 2018, a small statistically significant increase by an average of 0.8 percentage points in each subsequent year of survey $(p<0.001)$ is observed (see Fig. 1).

Although during the analysed period the use of seat belts in the rear seat has increased by an average of 2.4 percentage points with each survey year $(p<0.001)$, overall, they are usually used by only $54.7 \%$ of respondents $(N=5873 ; 95 \%$ CI $53,8-55,7)$ (see Fig. 2 ). 


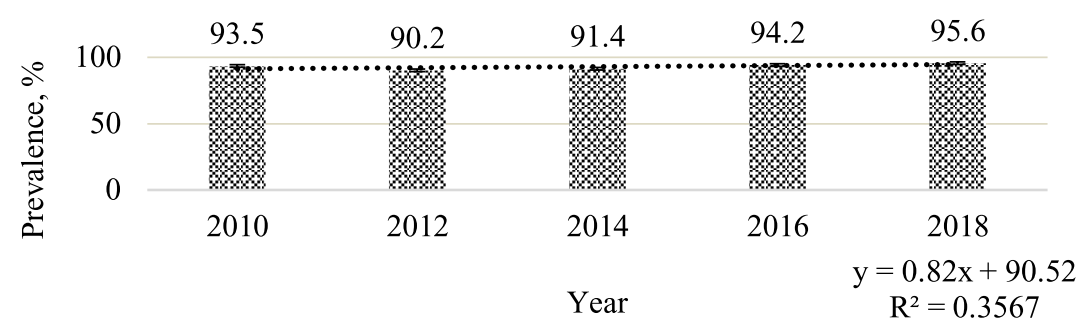

Figure 1. Point prevalence of the use of seat belts in the front seat from 2010 to 2018.

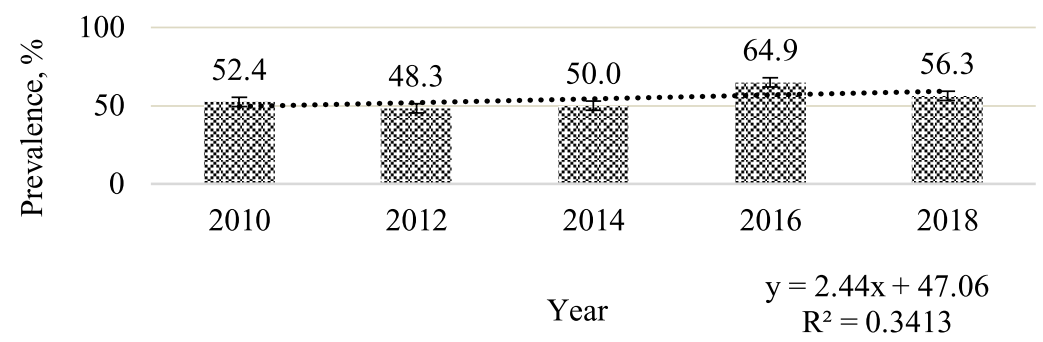

Figure 2. Point prevalence of the use of seat belts in the rear seat from 2010 to 2018 .

According to the World Health Organisation definition, excessive alcohol consumption is the use of at least 60 grams and more of pure alcohol at least once in the last month (30 days) (WHO, 2018). Of total 10,731 respondents, $14.8 \%(N=1593 ; 95 \%$ CI 14.2-15.5) had consumed at least six units of alcohol in a single setting last month. Analysing the trends in the period from 2010 to 2018 , a small statistically significant decrease by an average of 1.1 percentage points in each subsequent year of survey $(p<0.001)$ is observed (see Fig. 3).

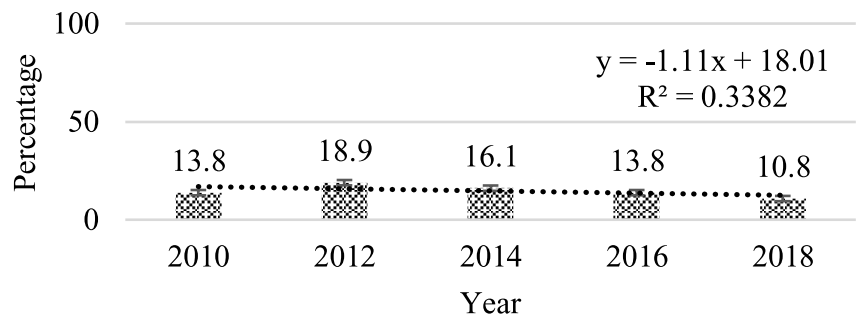

Figure 3. Percentage of excessive alcohol consumption from 2010 to 2018.

Analysing smoking index, data show there are 30.8\% $(N=3309 ; 95 \%$ CI $30.0-31.7)$ everyday smokers, $16.3 \%(N=1747 ; 95 \%$ CI 15.6-17.0) occasional smokers and $52.8 \%$ $(N=5663$; 95\% CI 51.9-53.8) non-smokers. The analysis of the trends in the period from 2010 to 2018 shows a small statistically significant decrease by an average of 2.3 percentage points in each survey year $(p<0.001)$ (see Fig. 4). 


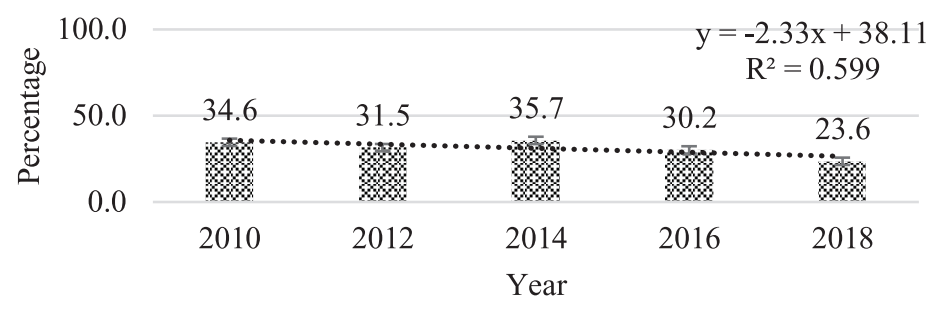

Figure 4. Percentage of everyday smokers in smoking index from 2010 to 2018.

Although during the analysed period percentage of respondents, who had not visited their family doctor in the past year, has decreased by an average of 3.8 percentage points with each survey year $(p<0.001)$, overall, $25.9 \%(N=2779$; 95\% CI 25.1-26.7) of respondents had not checked their health at family doctor last year (see Fig. 5).

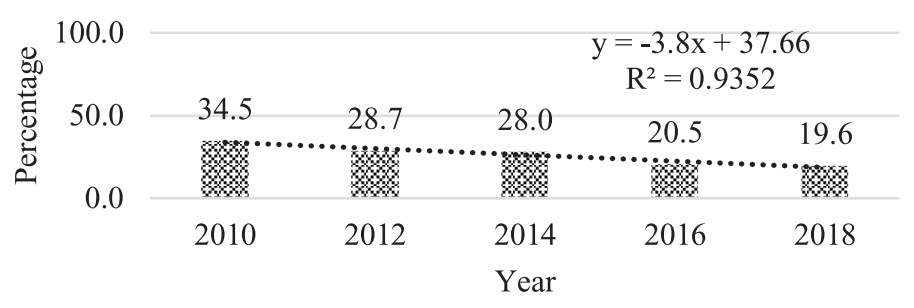

Figure 5. Percentage of respondents, who had not visited family doctor last year from 2010 to 2018.

The association between road safety habits and health behaviour was identified. Excessive alcohol use, smoking and not using state-provided preventive health services were considered as risky health behaviours.

Factors characterizing risky health behaviours reduce the odds for using the seat belt in the front seat of the vehicle by 1.3-2.1 times. In all years of the questionnaire, the trends in the use of seat belts in the vehicle's front seat in terms of alcohol consumption behaviours, smoking and in relation to the visit to a family doctor, have been similar. Respondents who had not excessively consumed alcohol in the last month, non-smokers, as well as respondents who had visited a family doctor in the last year, have higher odds of the use of seat belts in multivariate regression analysis, when adjusted for gender, age and level of education (see Table 1).

Respondents without excessive drinking behaviours, non-smokers, as well as respondents who had visited their family doctor in the last year, demonstrate 1.2-2.1 times higher odds of use of seat belts in the rear seat, even when adjusted for gender, age and educational level. During all years of the questionnaire, the trends in the use of seat belts in the vehicle's rear seat in terms of alcohol consumption behaviours, smoking and in relation to the visit to a family doctor, have been similar. The characteristics of the use of seat belt in the rear seat in relation to factors of health behaviours according to gender, age and level of education is shown in Table 2. 
Table 1. Number, proportion and odds ratio of the use of seat belt in the front seat in relation to factors of health behaviours.

\begin{tabular}{|l|l|c|l|}
\hline \multicolumn{2}{|c|}{ Factors } & $N(\%)$ & Adjusted OR (95\% CI) \\
\hline \multirow{2}{*}{$\begin{array}{l}\text { Excessive alcohol } \\
\text { consumption }\end{array}$} & No & $8623(94.4)$ & $2.1(1.7-2.5)^{* *}$ \\
\cline { 2 - 4 } & Yes & $1366(85.8)$ & 1.0 \\
\hline \multirow{3}{*}{ Smoking } & Non- smokers & $5402(95.4)$ & $1.8(1.5-2.2)^{* *}$ \\
\cline { 2 - 4 } & Others & $1633(93.5)$ & $1.5(1.2-1.8)^{* *}$ \\
\cline { 2 - 4 } & Everyday smokers & $2924(88.9)$ & 1.0 \\
\hline \multirow{2}{*}{$\begin{array}{l}\text { Family doctor } \\
\text { visits past year }\end{array}$} & Yes & $7952(93.9)$ & $1.3(1.1-1.5)^{*}$ \\
\cline { 2 - 4 } & No & $2779(90.6)$ & 1.0 \\
\hline
\end{tabular}

Adjusted OR: adjusted for gender, age and level of education

Reference category: the use of seat belts - sometimes/never

$* p<0.05 ; * * p<0.001$

Table 2. Number, proportion and odds ratio of the use of seat belt in the rear seat in relation to factors of health behaviours.

\begin{tabular}{|l|l|l|l|}
\hline \multicolumn{2}{|c|}{ Factors } & \multicolumn{1}{|c|}{$\boldsymbol{N ( \% )}$} & \multicolumn{1}{|c|}{ Adjusted OR (95\% CI) } \\
\hline \multirow{2}{*}{$\begin{array}{l}\text { Excessive alcohol } \\
\text { consumption }\end{array}$} & No & $5292(57.9)$ & $2.1(1.9-2.4) * *$ \\
\cline { 2 - 4 } & Yes & $581(36.4)$ & 1.0 \\
\hline \multirow{4}{*}{ Smoking } & Non-smokers & $3404(60.1)$ & $1.5(1.4-1.7) * *$ \\
\cline { 2 - 4 } & Others & $927(53.1)$ & $1.2(1.1-1.4) *$ \\
\cline { 2 - 4 } & Everyday smokers & $536(46.4)$ & 1.0 \\
\hline \multirow{2}{*}{$\begin{array}{l}\text { Family doctor } \\
\text { visits past year }\end{array}$} & Yes & $4501(56.6)$ & $1.2(1.1-1.3) * *$ \\
\cline { 2 - 4 } & No & $1371(49.3)$ & 1.0 \\
\hline
\end{tabular}

Adjusted OR: adjusted for gender, age and level of education Reference category: the use of seat belts - sometimes/never $* p<0.05 ; * * p<0.001$.

\section{Discussion}

This study has provided an analysis of the road safety habits of the adult population of Latvia in relation to such risky health behaviours as smoking, excessive alcohol consumption and no regular health check-ups at the family doctor from 2010 to 2018.

In all European Union Member States, the law requires the use of seat belts in a car [2] and, in the long term, this road safety behaviour has improved and has even become the norm in a large part of the public. Similarly to other countries [11], the analysis of this data shows that the proportion of seat belt use in the front seat of the vehicle in Latvia has improved over time and is gradually approaching the level of other European countries, exceeding 95\% in 2018. At the same time, a large proportion of the population did not use seatbelts in the rear seat in Latvia. Although the percentage of the seat belt usage in the rear seat has increased by 2 percentage points between 2010 and 2018 in each subsequent survey year, they are still usually used in general by only $53.6 \%$ of respondents, which is critically low, especially comparing to other European Union Member State countries. Due to the high fatality and injury rates in traffic collisions, these relatively low rates of seatbelts in Latvia have been set as one of the priorities in traffic safety [4].

Data shows that alcohol use and disorders associated with it are an important risk factor for injuries in road traffic increasing both the risk of collision and the severity of injuries 
multiple times [12]. World Health Organisation has been calling for increased attention and for policies to significantly restrict and reduce alcohol use by road users for decades (1). However, alcohol use is an overall problem, which reaches beyond road traffic safety, so in this study the traffic safety habits were studied in relation with overall consumption of alcohol. Risky alcohol use was defined for respondents who had taken at least six units of alcohol in a single drinking event during the last month. The analysis, made in this study, confirms that respondents without risky alcohol consumption behaviours have 2.1 times higher odds of using seat belts in both the front and rear seats of the vehicle. These findings are similar to other studies, where general risky behaviour, which includes both excessive use of alcohol and non-compliance with road safety, were studied [13-15].

Another risky health behaviour analysed in this study was smoking. The results confirm that everyday smokers have 1.5-1.8 times higher odds for use of the seat belts compared to non-smokers, including when adjusted for demographic and socio-economic factors consistent with studies in scientific literature. The observed association is explained by the fact that the two behaviours analysed - smoking and non-compliance with road safety regulations represent a risky attitude towards person's health. Data show that one of the most frequently observed distraction, while driving a car, has been seen to be smoking (the other two - passenger talks and mobile phone use) [16]. The observed association highlights the need to promote public policies and interventions aimed at increasing the number of smoke-free cars. It should be emphasized that there had been such discussions in Latvia. Still the law prohibits only smoking in public vehicles, while private vehicles have to comply with a smoking ban in public places, for example, a ban on smoking in the presence of a child and a pregnant woman currently [17].

Data on visits to the family doctor are included in the analysis of careless health behaviour. When adjusted for gender, age and level of education, respondents, who had visited their family doctor over the past year, have 1.2-1.3 higher odds of seat belt use compared with others. The evidence confirms that the most effective behavioural change interventions are those that are simultaneously and consistently targeted at both the general population and the community, as well as individual level, including primary health care [18]. The observed association in this study and the results from others $[19,20]$ show great potential for targeted interventions at the primary health care level to improve the habits of the population.

\section{Conclusions}

It is generally recognised that seat belt use is an important prevention for injuries and fatalities related to road traffic collisions. Public health and transportation professionals have sought to identify strategies how to improve that, especially reducing the gap with passengers in rear seats, where seat belt use remains consistently lower than in the front seats.

The results of this research confirm the association of the analysed health behaviour factors with poorer road traffic habits. Those least likely to use seatbelt both in the front and rear seats are excessive alcohol users, everyday smokers, and persons, who had not visited their family doctor during last year.

This highlights the need to combine public campaigns and enforcement with educational and development programs in the way to influence unsafe road habits among critical groups, for example everyday smokers and excessive alcohol users, and further improve road safety. More effort should be put in educating primary health professionals on the safety of the population in traffic related factors and behaviours, as well as creating significant long-term response to the reduction of injury and external causes of death. 


\section{References}

[1] World report on road traffic injury prevention, World Health Organization (2004)

[2] Global status report on road safety, World Health Organization (2018)

[3] Informatīvais ziṇojums "Ceḷ satiksmes drošības plāna 2017.-2020. Gadam starpposma ietekmes izvērtējums", Ministru kabinets, 2/20 (14.01.2020)

[4] Noteikumu projekts "Ceḷu satiksmes drošĩbas plans 2021.-2027.gadam”, Satiksmes ministrija (2021)

[5] Proposal for a Directive of the European Parliament and of Council about facilitating cross-border enforcement in the field of road safety, Commission of the European Communities, 351/2 (2008)

[6] L.F. Beck, R.A. Shults, Seat belt use in states and territories with primary and secondary laws-United States, 2006. Journal of Safety Research 40(6), 469-472 (2009)

[7] T.W. Strine, L.F. Beck, J. Bolen, C. Okoro, S. Dhingra, L. Balluz, Geographic and sociodemographic variation in self-reported seat belt use in the United States. Accident Analysis and Prevention 42(4), 1066-1071 (2010)

[8] J. Tison, A.F. Williams, N.K. Chaudhary, Daytime and nighttime seat belt use by fatally injured passenger vehicle occupants. (DOT HS-811-281), Washington, DC: National Highway Traffic Safety Administration (2010)

[9] G. Bhat, L. Beck, G. Bergen, M. Kresnow, Predictors of rear seat belt use among U.S. adults, 2012. Journal of Safety Research 53, 103-106 (2015)

[10] National Highway Traffic Safety Administration. Motor Vehicle Occupant Safety Survey (2007)

[11] International Expert Network and Database on Road Safety. Road Safety Annual Report 2017. Organisation for Economic Cooperation and Development (2017)

[12] H.S. Kim, H.J. Kim, B. Son. Factors associated with automobile accidents and survival. Accident Analysis and Prevention. 38(5), 981-987 (2006)

[13] A. Jewett, R.A. Shults, T. Banerjee, G. Bergen, Alcohol-impaired driving among adults - United States, 2012. Morbidity and Mortality Weekly Report. 64(30), 814-817 (2015)

[14] W. Liang, T. Chikritzhs, Examining the Relationship between Heavy Alcohol Use and Assaults: With Adjustment for the Effects of Unmeasured Confounders. BioMed Research International. 10 (2015)

[15] C. Liu, Y. Huang, J. Pressley, Restraint use and risky driving behaviors across drug types and drug and alcohol combinations for drivers involved in a fatal motor vehicle collision on U.S. roadways. Injury Epidemiology. 3(1), 1-9 (2016)

[16] M.J. Sullman, An observational study of driver distraction in England. Transportation Research Part F: Traffic Psychology and Behaviour 15(3), 272-278 (2012)

[17] Tabakas izstrādājumu, augu smēkēěanas produktu, elektronisko smēkēěanas ierīču un to škidrumu aprites likums, Latvijas Véstnesis 91(12.05.2016)

[18] Behaviour Change at Population, Community and Individual Levels [NICE Public Health Guidance 6]. London: National Institute for Health and Care Excellence (2007)

[19] E.M. Ozer, S.H. Adams, J.K. Orrell-Valente, C.J. Wibbelsman, J.L. Lustig, S.G. Millstein, C. Irwin, Does Delivering Preventive Services in Primary Care Reduce Adolescent Risky Behavior? Journal of Adolescent Health. 49(5), 476-482 (2011)

[20] Capturing Social and Behavioral Domains and Measures in Electronic Health Records: Phase 2. Institute of Medicine and Board on Population Health Public Health Practice (2014) 